NBER WORKING PAPER SERIES

\title{
DO CITIZENS WANT THE TRUTH ABOUT TERRORIST THREATS REGARDLESS OF THE CONSEQUENCES?
}

\author{
V. Kerry Smith \\ Carol Mansfield \\ H. Allen Klaiber \\ Working Paper 16232 \\ http://www.nber.org/papers/w16232
NATIONAL BUREAU OF ECONOMIC RESEARCH
1050 Massachusetts Avenue
Cambridge, MA 02138
July 2010

Thanks are due Michael Kaminsky and Eric Stewart for excellent research assistance related to this work and to Natalie Cardita for assistance in preparing several drafts of this paper. The research was supported by the United States Department of Homeland Security through the Center for Risk and Economic Analysis of Terrorism Events (CREATE) under grant numbers 2007-ST-061-000001 and DE-AC05-76RL01830. However, any opinions, findings, and conclusions or recommendations in this document are those of the authors and do not necessarily reflect the views of the United States Department of Homeland Security, nor those of the National Bureau of Economic Research.

NBER working papers are circulated for discussion and comment purposes. They have not been peerreviewed or been subject to the review by the NBER Board of Directors that accompanies official NBER publications.

(C) 2010 by V. Kerry Smith, Carol Mansfield, and H. Allen Klaiber. All rights reserved. Short sections of text, not to exceed two paragraphs, may be quoted without explicit permission provided that full credit, including $\odot$ notice, is given to the source. 
Do Citizens Want the Truth about Terrorist Threats Regardless of the Consequences?

V. Kerry Smith, Carol Mansfield, and H. Allen Klaiber

NBER Working Paper No. 16232

July 2010

JEL No. D61,H41,H56

\section{ABSTRACT}

This paper proposes the use of consumers' preferences in formulating policies for keeping secret information about terrorist activities and threats that might compromise future security. We report the results from two surveys indicating that people have clear preferences for full disclosure of some terrorist related information regardless of its consequences for specific industries or future threats. This result is especially clear for threats involving commercial airlines. For those threats associated with more general surveillance or threats to the financial system respondents were more willing to allow government authorities to withhold information.

V. Kerry Smith

Department of Economics

W.P. Carey School of Business

P.O. Box 873806

Arizona State University

Tempe, AZ 85287-3806

and NBER

kerry.smith@asu.edu

Carol Mansfield

RTI International

3040 Cornwallis Rd.

PO Box 12194

Research Triangle Park, NC 27709

carolm@rti.org
H. Allen Klaiber

Department of Agricultural Economics and Rural Sociology

208A Armsby Buliding

Pennsylvainia State University

University Park, PA 16802

aklaiber@psu.edu 
Do Citizens Want the Truth About Terrorist Threats Regardless of the Consequences? V. Kerry Smith, Carol Mansfield, and H. Allen Klaiber

\section{Introduction}

It is widely assumed that security requires some amount of secrecy. Even in a free society, most people recognize the need for governments to keep some information secret to protect their citizens. But how much is enough and how do people react when the information involved is about terrorist threats? This paper reports the first national survey of people's attitudes toward public deception in the name of security. ${ }^{1}$

Many discussions of the criteria for limiting the disclosure of information in a democracy are based on conceptual arguments. They consider the relative importance of accountability and policy effectiveness when full information disclosure contributes positively to the first objective and may have negative impacts for the second. Secrecy has increased since the September 11, 2001 attacks in the U.S. because it is argued that public disclosure of the government's private information related to anything that might compromise security will increase terrorist risks. Priest and Arkin's [2010] series in The Washington Post on the privatization of national security is a notable example of one of the effects of these policies. Their first installment highlights the significant role of private companies in homeland security operations, a situation that has been largely unknown to the public.

\footnotetext{
${ }^{1}$ Viscusi and Zeckhauser [2003] conducted a survey of law students' attitudes toward security screenings and other infringements on civil liberties as measures intended to reduce terrorist threats.
} 
In another context, Shapiro and Siegel's [2010] analysis of the arguments for secrecy use models of the strategic actions of the government and of terrorists, as interacting agents. They recommend a nuanced approach in evaluating policies that call for increased secrecy in the name of security. In their analysis information is grouped into broad types- organizational, general, and target specific. Their models do not offer unambiguous criteria for disclosure versus secrecy. Nonetheless, their analysis does suggest the analysis should consider the type of information that is being kept secret and the net benefits of disclosure, weighing the increased risks against the potential for an enhanced ability to protect the public due to better use of information ${ }^{2}$.

The analysis we report in this paper is based on a survey of Knowledge Network's panelists in thirty-three large metropolitan areas conducted in late 2009 and early 2010 . While our survey was developed before we became aware of the Shapiro and Siegel findings, the design poses questions that complement the logic of their analytical structure. Shapiro and Siegel's models assume the government agent reflects the preferences of the population at risk. These preferences are assumed to depend on reducing the risk of a successful attack. Our survey findings suggest the public's preferences are more complex. The respondents want some types of information revealed regardless of the consequences for future risks. As a result the criteria for information disclosure need to consider the preferences of the people facing the increased risk that disclosure creates.

These responses do not appear to be due to cognitive mistakes and vary with the type of information that would need to be withheld. Thus, even if the net benefits from enhanced

\footnotetext{
${ }^{2}$ Recent work by Abadie and Dermisi [2008] is based on the maintained assumption that people assess the risks of future terrorist actions based on the past. In this study they use commercial office vacancy rates to assess whether vacancies are higher in business locations near "signature" buildings with the potential for greater terrorist threats. This type of logic is another reason why we focused our sample on respondents from large metropolitan areas.
} 
efficiency in the government's responses to threats with information were small compared to the risks, people will prefer full disclosure of certain types of information. Our findings indicate that disclosing information about threats to commercial airlines is especially important to the survey respondents.

Section two provides some highlights of the literature on the criteria for withholding information in a democracy. Section three describes our survey. Section four summarizes our findings and the last discusses their implications.

\section{Information and Security Externalities}

Government secrecy may seem inconsistent with the principles that define a democratic society. However, the issues involved in public management of information dissemination in a free society are complex. Most scholars considering the subject argue that some limits to full information disclosure are essential. Thompson [1999], for example, described the inherent dilemma as having two parts:

“...democracy requires publicity, but some democratic policies require secrecy. The first horn [of this dilemma] is familiar enough: The policies and processes of government must be public in order to secure the consent of the governed. ... the second horn points to the fact that some policies and processes, if they were made public, could not be carried out as effectively or at all. These policies and processes may well be ones to which citizens would consent if they had the opportunity" (p. 182, bracketed term added).

Homeland security policy since September 11, 2001, has focused renewed attention on the question of government secrecy. Thompson's description applies nicely to debates over when information should be kept secret for national security reasons. 
Shapiro and Siegel [2010] address the question of information disclosure in a more formal modeling framework ${ }^{3}$. They use models of the strategic interaction between two players to analyze the conditions under which information should or should not be kept secret. They use a model with two agents. The first represents the government. This agent must decide whether to release different types of information. The second represents all the terrorists grouped as a single "player" who would use the information to "destroy, incapacitate or exploit critical infrastructure across the United States to threaten national security...."4 The authors consider whether information provided by the government will be a net benefit to the society that has the information and faces the threat from terrorists. Their analysis reviews three different types of information:

(1) Organizational Information- This is described as information that would help the government predict terrorists' operating patterns.

(2) General Information- This information need not be associated with terrorism directly. It could be associated with accountability of governing units and anticipating shortfalls in service. They cite research uncovering capacity limits or key nodes in telecommunications infrastructure that serves to identify limitations before they create problems. Such anticipatory research could also convey general information about weaknesses of the system.

(3) Target Specific Information- Systems that allow the reporting of vulnerabilities of key facilities to threats and can be effective in reducing those limitations.

\footnotetext{
${ }^{3}$ Shapiro and Siegel [2008] is a mathematical appendix to their paper which provides the details for the models underlying their conclusions.

${ }^{4}$ Shapiro and Siegel cite Homeland Security Presidential Directive seven as the source of a redefinition following September 11, 2001, of the scope of secrecy in the name of national security. See discussion pp 67-68 and note \#4.
} 
In all three classes of information, the dissemination of information has both positive and negative effects. Sharing organizational and general information allows more people to work on the issues and, as a result, increases the chances of improved responses to specific terrorist threats or system vulnerabilities. Of course, as several authors have noted, ${ }^{5}$ the terrorists are also using the freely available information. When the protecting agent and the agent seeking to disable interact continuously, the realized risks (and outcomes) are the result of the sequence of strategic interactions. Once information is released the interactions change because terrorists can react. Given that terrorists will react, the outcomes resulting from the government's decisions to release information, the form in which the information is released, and the government's protective responses become endogenous variables to the model.

Using the case of organizational information as an example of this endogeneity, consider the government's acknowledgment of a database on terrorist actions and research about terrorists based on that data. Knowing the existence of this information creates incentives for terrorists to change tactics, reducing either the value of the database or the incentives to study the data. As another example, identifying "weak links" as either general information or target specific information offers opportunities to fix them, but also provides ideas to the terrorists of potential targets.

In the end Shapiro and Siegel conclude favoring a more nuanced approach to information policy and suggest:

\footnotetext{
${ }^{5}$ Enders and Sandler [2006] offer the most complete overview of the literature and in chapters five and six specifically discuss the ways information influence terrorist responses. In chapter six the specific focus on transnational terrorism and the failure to share information across the autonomous agencies protecting individual countries offers an example of the Shapiro Siegel argument. Zhuang and Bier [2010] offer a brief summary of some of the more recent literature on strategic models of government terrorist interactions.
} 
"Under a wide range of conditions, open sharing of government's private information can enhance efforts to protect citizens. This is true even when the information deals directly with specific targets. When the positive externalities of information sharing are taken into account, the set of conditions under which open information sharing benefits society become wider still. Our analysis puts to rest the overly simple conception that revealing vulnerabilities to the other side is strictly a poor idea." (p. 96, emphasis added).

The conclusion follows in part from an assumption that the "publicness" of the information allows the government agent to act "faster" and "better" than the terrorist. That is, the government has the opportunity to take advantage of insights from many sources through coordinated use of what is learned. With more people looking at problems or with greater "light on problems" there are more likely to be solutions and/or actions to address them. ${ }^{6}$ The government "benefits" from public release of information because it can make greater use of the information as data and can coordinate responses as a result.

This logic is actually not a part of their formal model. Nonetheless, it is consistent with their focus on technical features of the interaction. The strategic interaction in their model is about factors influencing the ability of the government to "produce" protection. People's preferences may be more multi-faceted with different concerns about disclosure about specific types of information. One reason stems from differences in the ability to self-protect across different people. Another arises with heterogeneity in the assessment of different types of theorist risks. These extensions are important if the general public does display marked differences in their attitudes toward disclosing different types of information and provide the motivation for our survey.

\footnotetext{
${ }^{6}$ This assessment is based on the explanations described in the Shapiro-Siegel [2010] paper not their mathematical appendix to the paper. The appendix (Shapiro and Siegel [2008]) is a more narrowly focused set of two person game-theoretic models developed in expected utility terms where the odds of specific actions being effective depend on the other agent's behavior including information disclosure.
} 


\section{A Survey on the Merits of Secrecy}

This section describes a survey to assess the public's tolerance for government secrecy under different conditions. The survey was structured as part of a larger study on the benefits of homeland security policies. As part of the questionnaire, each respondent was asked whether they would support allowing the government to keep information secret given a set of conditions. Figure 1 contains the wording of the three questions with scenarios presenting different types of information and consequences. Each scenario must have some elements of specific types of events to establish the context. As a result, a designation of each one as an example of the Shapiro-Siegel categories will be imperfect. We regard version B as similar to what Shapiro and Siegel label as target specific information. Version A, an airport surveillance system, is closer to the organizational information category. Version $\mathrm{C}$ has elements of both but a generic surveillance system is highlighted specifically in this scenario as well. Each information scenario also includes a statement about the likelihood that announcing details of the information collected as part of reducing the threat of some terrorist action could reduce the ability to protect against future threats of that type. Each respondent was randomly assigned one of three scenarios. Each person also received one of three probabilities ( 1 in 5 chances, 1 in 10 chances and 1 in 100 chances) that the negative externality due to the information disclosure would occur. The respondents were asked whether they would favor announcing the information or keeping the details secret.

Our survey was implemented in two phases using a web-based instrument to members of the Knowledge Networks panel. ${ }^{7}$ Unlike most other internet panels, Knowledge Networks

\footnotetext{
${ }^{7}$ The survey instrument was developed and tested in four focus groups and through a pre-test involving 222 panelists, 18 years and older, who lived in the metropolitan areas of Kansas City and Los Angeles. The pre-test
} 
recruits a representative sample of households onto their panel through Random-Digit Dialing and, more recently, through address-based sampling. Households that do not have a computer are provided with a computer and internet access. Households with a computer are provided with free internet access.

The survey was first sent to a sample of panelists aged 18 and over who lived in one of 33 metropolitan areas between December 15, 2009, and December 31, 2009. ${ }^{8}$ Seventy-one percent of those invited responded to yield a sample with 1901 panelists $^{9}$. Major metropolitan areas were selected for the sample, based in part on the discussions during survey pretests indicating that most people felt terrorist threats were most salient for those living or working in large metropolitan areas.

A follow-up survey of 482 different panelists in four of the metropolitan areas involved in the first sample was conducted between April 1, 2010 and April 19, 2010. The same survey instrument was used for both surveys. This second survey allowed assessment of whether the events surrounding the Christmas bomber influenced the panelists' attitudes toward secrecy. ${ }^{10}$

indicated respondents were able to answer the questions and understood the materials presented. The questionnaire was shortened to accommodate budget restraints.

${ }^{8}$ The thirty-three metropolitan areas were: Atlanta, GA; Boston, MA; Buffalo, NY; Charlotte, NC; Chicago, IL; Columbia, MO; Dallas, TX; Detroit, MI; Greenville, SC; Houston, TX; Huntsville, AL; Kansas City, KS; Las Vegas, NV; Lincoln, NE; Los Angeles, CA; Miami, FL; Mobile, AL; Nashville, TN; New Orleans, LA; New York City, NY; Norfolk, VA; Oklahoma City, OK; Phoenix, AZ; Pittsburgh, PA; Raleigh, NC; Richmond, VA; San Diego, CA; San Francisco, CA; Seattle, WA; St. Louis, MO; Tallahassee, FL; Tampa, FL; Washington, D.C.

${ }^{9}$ The overall response rate for Knowledge Networks surveys is below $10 \%$ if one accounts for the entire panel recruiting process, which includes many steps at which panel members could drop out. Smith et al [2009] discuss in the appendix to their paper the recruiting process for the Knowledge Network panels and the analysis of selection effects associated with this process. The research record to date suggests that while the Knowledge Network panel is systematically different from the U.S. population as a whole due to non-response, this process has not impacted the assessment of risks, characterization of individual preferences for policies that affect nonmarket environmental services or security risks.

${ }^{10}$ On December 25, 2009, an attempt to destroy a Northwest passenger jet bound for Detroit was unsuccessful. The event received extensive news coverage in the months after it took place. Two hundred and thirty of our panelists in the first sample completed their interviews after the event. We investigated whether their responses 
Table 1 summarizes the demographic characteristics of the respondents to the two surveys. The first column reports summary attributes and attitudes of the full December 2009 sample. Four metropolitan areas, Chicago, the District of Columbia, Los Angeles, and New York, were oversampled in this survey. These areas were the focus of the second survey in April 2010. The second column provides a summary of characteristics for these four areas' panelists in the December 2009 survey and the third column reports the same summary statistics for the independent panelists from these areas who participated in the April survey. As these summary results suggest, the panelists are broadly similar in their demographic characteristics, education, income, and attitudes toward personal responsibility for being prepared for a variety of uncontrollable threats. Considering the summary statistics in Table 1, most of the sample are between 35 and 64 (over 75 years of age is the omitted category in the table). The majority are white and married. Slightly greater than half of the respondents have a college degree or higher and household income levels are higher than the U.S. average. The majority felt it was very or somewhat important to be prepared for disasters.

\section{4. $\underline{\text { Results }}$}

The first row in Table 1 reports the proportion of respondents in each sample who favored full government disclosure of information (publicizing the truth) when we combine the responses from all three of the scenarios. The results suggest that somewhat less than half the

were different from those completing the survey before December $26^{\text {th }}$. There was no difference in their responses. This was tested using simple chi-square tests as well as in the more extensive multivariate model. As a result we focus our attention on the analysis of the second survey with added time to consider all of the news and discussion of terrorism threats. 
respondents would favor information disclosure. This result holds for higher risk metro areas as sub-samples as well as over time in these four higher risk metropolitan areas.

However, this general result is misleading. As Table 2 suggests, there are dramatic differences in this willingness to accept secrecy across different types of threats. The three panels in Table 2 provide the most direct summary of our primary findings. Adult residents of major metropolitan areas likely to be potential terrorist targets do not accept blanket secrecy policies for different types of information. There is a sharp and persistent difference in their attitudes toward public secrecy that depends on the nature of the information describing the terrorist target.

Policies that would withhold information about terrorist plots involving commercial airlines would not be acceptable to over eighty percent of the respondents asked about them. The rate observed for respondents from Chicago, the District of Columbia, Los Angeles, and New York did not change after the Christmas day attempted bombing of a commercial flight bound for Detroit. Information associated with incidents involving surveillance systems that disrupted terrorists at airports or with the financial system could be withheld from the perspective of the majority of respondents receiving them. The percentage willing to withhold this information was over seventy-five percent and stable across sub-samples and time periods.

Changes in the likelihood of information impacting future safety did increase the acceptability of secrecy for incidents involving the commercial airline system. Nonetheless, this effect was small and respondents did not discriminate between odds of one in five compared to one in ten. The primary finding from varying the stated likelihood of future effects was an increased propensity for full disclosure at the lowest odds of disruption from making the information public, when compared to either of two higher odds cases. This result implies that 
people did understand the external effect of information disclosure. Higher risk of effects reduced the demands for disclosure but the effect was not large enough to change general sentiment for full disclosure in the case of threats to commercial airlines.

These findings are quite robust and make no assumptions about perceptions of the importance of the secrecy or the reasons why availability of information might be important to Knowledge Network panelists. They assume each respondent receiving one of the nine treatments can be treated as approximately equivalent to any other. Table 4 investigates whether observable features of panelists' heterogeneity influences our findings. This assessment fits probit models to panelist responses to the information disclosure questions. The model hypothesizes that a response favoring full disclosure is a function of the type of informationorganizational (Versions A and, potentially, C), target specific associated with the commercial airline system (Version B). We also include fixed effects for two of the three odds of disruption (so the parameters measure the effect compared to the omitted category). Our probit model is restricted to exclude an intercept. This normalization allows us to identify separate estimates for the effect of each version rather than to estimate a comparative effect (i.e. relating the included terms to the omitted category). Our conclusions would not change with an alternative normalization.

The models include age class fixed effects, gender, a variable identifying whether the respondent's household had young children, race, education fixed effects, marital status, household income and a count of the number of emergency preparedness actions they have taken. ${ }^{11}$ This last variable is intended to serve as an indicator of their concerns about hazards and

\footnotetext{
${ }^{11}$ The question asked respondents about a list of things people have done to prepare for disasters including: have a first aid kit, have a weeks supply of personal care and hygiene products, have a 7-day supply of prescriptions,
} 
propensity to self protect. Finally we estimated the basic model using the full sample with and without fixed effects for the thirty-three metropolitan areas.

The findings confirm the results from our simpler cross tabulations. After controlling for age, gender, race, income, and the likelihood of disruption, these respondents consistently support disclosure of information concerning terrorist threats to the airline system, regardless of consequences described as leading to damage and potential destruction of a viable commercial airline sector. By contrast, they would support withholding information that was general about surveillance methods. In addition information could be withheld about a surveillance system that reduces the threat of disruption to the credit system.

We considered the model using the full sample (both December 2009 and April 2010 surveys) and found the airline related threat between the surveys associated with the incident labeled the Christmas bomber, did not influence attitudes toward disclosing airline information. The interaction variable defined as the product of the fixed effect for Version B and one indicating that the respondent was part of the second survey was not significant. Controlling for metropolitan areas did not influence our conclusions (see column (2)). Similarly restricting the sample to the four metro areas before (column (3)) or after the Christmas bombing threat (column (4)) did not alter the general findings.

Our ability to isolate the effects of demographic variables was influenced by sample size. It appears women are more willing to support withholding information. Those with at least a college degree are not. Married households are more willing to allow limits on information

have a radio with fresh batteries, designate a contact outside the area, and have a two week supply of food and water. This variable is a count of the number each respondent indicated they had available. 
disclosure. Otherwise, support for treating the disclosure of different types of terrorist related information differently is quite uniform.

Thus, these results imply that the Shapiro-Siegel "nuanced policy" should consider people's views about the type of information they indicate should be disclosed and not assume strategic models of government and terrorist interactions in response to information can be interpreted independent of context for the information. People display significantly different preferences for full disclosure of terrorist related information.

\section{5. $\underline{\text { Implications }}$}

There are certainly limits to full information disclosure in free democratic societies. Many observers have argued the 9/11 attacks lead to significant increases in calls for secrecy as essential to homeland security. Political scientists have considered the properties of alternative decision criteria that can be applied in making the choices about when Democratic governments can reasonably withhold information from citizens. Based on formal models of the strategic interaction between two agents, the government and a terrorist entity, along with informal contextual analysis, Shapiro and Siegel argue against increased secrecy in favor of a more nuanced policy. They suggest, given the assumptions of their analysis, that open access to most types of information is likely to yield greater benefits to a threatened society like the U.S. than most forms of secrecy.

Our analysis suggests their discussion and most of the earlier work on limits to information disclosure leave out the preferences of the citizens who would be affected by these choices. That is, the strategic analyses take as given that the government "agent" in these models 
can be adequately described by assuming the primary concern is avoiding a successful attack of any type.

We began our analysis with the premise that people have different demands for information about different types of threats. As a result, even if the government is assumed to be equally effective in responding to all types of threats and that information disclosure would be equally damaging, regardless of the type involved, people might nonetheless want to have information in some situations regardless of the consequences. Our survey results support this hypothesis. Respondents were especially concerned about full disclosure when the events involved threats to the commercial airline system. Comparable descriptions of threats to the effectiveness of a terrorist surveillance system or to compromising the credit system yielded much greater willingness to accept secrecy.

\section{References}

Abadie, Alberto and Sofie Dermisi, 2008, "Is terrorism eroding agglomeration economies in Central Business Districts? Lessons from the office real estate market in downtown Chicago" Journal of Urban Economics, Vol. 64 (2):451-462.

Enders, Walter and Todd Sandler, 2006, the Political Economy of Terrorism (New York: Cambridge University Press).

Priest, Dana and William M. Arkin, 2010, “Top Secret America: National Security Inc.” The Washington Post, July 20. (on line edition, http://projects.washingtonpost.com/top-secretamerica/articles/national-secruity-inc/)

Shapiro, Jacob N. and David A. Siegel, 2010, "Is this Paper Dangerous? Balancing Security and Openness in Counter Terrorism" Security Studies, Vol. 19 (1): 66-98.

Shapiro, Jacob N. and David A. Siegel, 2008, "Mathematical Appendix for Is this paper Dangerous" dated October 15, Unpublished paper accessed July 2010, J.N. Shapiro’s webpage. 
Smith, V. Kerry, Carol Mansfield and Laurel Clayton, 2009, "Valuing Homeland Security Policy: Countermeasures for the Threats from Shoulder Mounted Missiles," Journal of Risk and Uncertainty, Vol. 38, (June): 215-243.

Thompson, Dennis F., 1999, “Democratic Secrecy,” Political Science Quarterly, Vol. 114 (2) (Summer): 181-193.

Viscusi, W. Kip and Richard J. Zeckhauser, 2003, "Risk Beliefs" Sacrificing Civil Liberties to Reduce Terrorism Risk,” Journal of Risk and Uncertainty, Vol. 26 (March/May): 99-120.

Zhuang, J. and V.M. Bier, 2010, "Reasons for Secrecy and Deception in Homeland-Security Resource Allocation," Risk Analysis, forthcoming. 
Table 1: Descriptive Statistics

\begin{tabular}{|c|c|c|c|}
\hline \multirow[t]{2}{*}{ Variable } & \multicolumn{2}{|c|}{ Dec 2009} & \multirow{2}{*}{$\begin{array}{c}\text { April } 2010 \\
\text { Four Metro } \\
\text { Areas }\end{array}$} \\
\hline & Full Sample & Four Metro Areas & \\
\hline $\begin{array}{c}\text { Proportion Who Favored } \\
\text { Full Information } \\
\text { Disclosure } \\
\end{array}$ & 0.428 & 0.433 & 0.419 \\
\hline \multicolumn{4}{|l|}{ Age (fixed effects) } \\
\hline $18-24$ & 0.020 & 0.028 & 0.025 \\
\hline $25-34$ & 0.086 & 0.092 & 0.091 \\
\hline $35-44$ & 0.143 & 0.146 & 0.172 \\
\hline $45-54$ & 0.241 & 0.256 & 0.2670 \\
\hline $55-64$ & 0.270 & 0.256 & 0.243 \\
\hline $65-74$ & 0.176 & 0.163 & 0.149 \\
\hline Female & 0.586 & 0.570 & 0.629 \\
\hline Young Children & 0.092 & 0.090 & 0.108 \\
\hline No. of Children & 0.472 & 0.482 & 0.531 \\
\hline White & 0.772 & 0.717 & 0.703 \\
\hline No-High School & 0.020 & 0.026 & 0.014 \\
\hline College & 0.518 & 0.548 & 0.612 \\
\hline Married & 0.576 & 0.536 & 0.517 \\
\hline Income & 82,174 & 93,659 & 97,037 \\
\hline \multicolumn{4}{|l|}{$\begin{array}{l}\text { Importance of Being } \\
\text { Prepared for Disasters }\end{array}$} \\
\hline Very Important & 0.51 & 0.53 & 0.54 \\
\hline Somewhat Important & 0.43 & 0.40 & 0.40 \\
\hline Not too Important & 0.05 & 0.06 & 0.05 \\
\hline Not at all Important & 0.01 & 0.01 & 0.01 \\
\hline
\end{tabular}


Table 2: Cross-Tabulations- Version and Sample

\begin{tabular}{|c|c|c|c|c|}
\hline \multicolumn{5}{|c|}{ December, 2009 Sample } \\
\hline & \multicolumn{3}{|c|}{ Version } & \multirow[b]{7}{*}{$\begin{array}{l}\chi^{2}=596.3 \\
(p-\text { value }=0.00)\end{array}$} \\
\hline & A & $\mathrm{B}$ & $\mathrm{C}$ & \\
\hline \multirow{2}{*}{ Disclose Information } & 145 & 511 & 157 & \\
\hline & 0.23 & 0.83 & 0.24 & \\
\hline \multirow{2}{*}{ Withhold Information } & 486 & 107 & 495 & \\
\hline & 0.77 & 0.17 & 0.76 & \\
\hline & & & & \\
\hline \multicolumn{5}{|c|}{ December, 2009 Sample for Chicago, DC, Los Angeles, New York } \\
\hline & \multicolumn{3}{|c|}{ Version } & \multirow[b]{7}{*}{$\begin{array}{l}\chi^{2}=198.5 \\
(p-\text { value }=0.00)\end{array}$} \\
\hline & A & $\mathrm{B}$ & $\mathrm{C}$ & \\
\hline \multirow{2}{*}{ Disclose Information } & 48 & 180 & 54 & \\
\hline & 0.22 & 0.81 & 0.25 & \\
\hline \multirow{2}{*}{ Withhold Information } & 167 & 41 & 161 & \\
\hline & 0.78 & 0.19 & 0.75 & \\
\hline & & & & \\
\hline \multicolumn{5}{|c|}{ April, 2010 Sample for Chicago, DC, Los Angeles, New York } \\
\hline & \multicolumn{3}{|c|}{ Version } & \\
\hline & A & $\mathrm{B}$ & $\mathrm{C}$ & \\
\hline \multirow{2}{*}{ Disclose Information } & 43 & 119 & 40 & \\
\hline & 0.26 & 0.82 & 0.24 & \\
\hline \multirow{2}{*}{ Withhold Information } & 125 & 27 & 128 & \multirow[b]{3}{*}{$\begin{array}{l}\chi^{2}=135.0 \\
(p-\text { value }=0.00)\end{array}$} \\
\hline & 0.74 & 0.18 & 0.76 & \\
\hline & & & & \\
\hline
\end{tabular}


Table 3: Probit Estimates for Tell Truth Models by Sample with Type of Information Disclosure ${ }^{\mathrm{a}}$

\begin{tabular}{|c|c|c|c|c|}
\hline \multirow[b]{2}{*}{ Variables } & \multicolumn{2}{|c|}{ Full Sample } & \multirow{2}{*}{$\begin{array}{c}\text { Dec } 2009 \\
(3)\end{array}$} & \multirow{2}{*}{$\begin{array}{c}\text { April } 2010 \\
(4) \\
\end{array}$} \\
\hline & (1) & (2) & & \\
\hline \multirow{2}{*}{$\begin{array}{l}\text { A-Organizational } \\
\text { Information }\end{array}$} & -0.85 & -0.78 & -0.77 & -0.70 \\
\hline & $(-4.07)$ & $(-4.33)$ & $(-2.02)$ & $(-1.67)$ \\
\hline \multirow{2}{*}{ B-Commercial Airlines } & 0.88 & 0.93 & 0.94 & 1.01 \\
\hline & $(4.15)$ & $(5.05)$ & $(2.46)$ & $(2.32)$ \\
\hline \multirow{2}{*}{ C-Credit System } & -0.80 & -0.74 & -0.66 & -0.74 \\
\hline & $(-3.87)$ & $(-4.12)$ & $(-1.76)$ & $(-1.69)$ \\
\hline \multirow{2}{*}{ Air * April Survey } & -0.05 & -0.04 & - & - \\
\hline & $(-0.33)$ & $(-0.28)$ & - & - \\
\hline \multirow{2}{*}{$\mathrm{P}$-disrupt $=1 / 5$} & 0.06 & 0.07 & 0.19 & 0.04 \\
\hline & $(0.87)$ & $(0.98)$ & $(1.38)$ & $(0.25)$ \\
\hline \multirow{2}{*}{ P-disrupt= 1/100 } & 0.19 & 0.19 & 0.28 & 0.14 \\
\hline & $(2.69)$ & $(2.61)$ & $(2.07)$ & $(0.84)$ \\
\hline \multirow{2}{*}{ Age $18-24$} & 0.49 & 0.47 & 0.64 & -0.46 \\
\hline & $(1.88)$ & $(1.80)$ & $(1.39)$ & $(-0.75)$ \\
\hline \multirow{2}{*}{ Age $25-34$} & 0.26 & 0.22 & -0.10 & 0.12 \\
\hline & $(1.55)$ & $(1.38)$ & $(-.032)$ & $(0.32)$ \\
\hline \multirow{2}{*}{ Age $35-44$} & 0.38 & 0.36 & 0.38 & 0.28 \\
\hline & $(2.54)$ & $(2.44)$ & $(1.30)$ & $(0.87)$ \\
\hline \multirow{2}{*}{ Age $45-54$} & 0.23 & 0.20 & -0.10 & 0.07 \\
\hline & $(1.63)$ & $(1.50)$ & $(-0.40)$ & $(0.21)$ \\
\hline \multirow[b]{2}{*}{ Age 55-64 } & 0.17 & 0.15 & 0.15 & -0.07 \\
\hline & $(1.24)$ & $(1.17)$ & $(0.59)$ & $(-0.23)$ \\
\hline \multirow{2}{*}{ Age $65-74$} & 0.19 & 0.18 & 0.08 & 0.13 \\
\hline & $(1.31)$ & $(1.34)$ & $(0.28)$ & $(0.38)$ \\
\hline \multirow{2}{*}{ Female } & -0.20 & -0.20 & -0.26 & -0.18 \\
\hline & $(-3.29)$ & $(-3.34)$ & $(-2.23)$ & $(-1.29)$ \\
\hline \multirow{2}{*}{ Young Children } & -0.14 & -0.16 & -0.26 & -0.48 \\
\hline & $(-1.34)$ & $(-1.50)$ & $(-1.19)$ & $(-2.05)$ \\
\hline \multirow{2}{*}{ White } & 0.04 & 0.03 & -0.17 & 0.03 \\
\hline & $(0.47)$ & $(0.30)$ & $(-0.97)$ & $(0.15)$ \\
\hline \multirow{2}{*}{ African American } & -0.13 & -0.16 & -0.29 & -0.28 \\
\hline & $(-1.06)$ & $(-1.33)$ & $(-1.26)$ & $(-1.17)$ \\
\hline \multirow{2}{*}{ No-High School } & -0.05 & -0.04 & -0.01 & -0.30 \\
\hline & $(-0.23)$ & $(-0.17)$ & $(-0.02)$ & $(-0.43)$ \\
\hline \multirow{2}{*}{ At Least College } & 0.19 & 0.18 & 0.25 & 0.24 \\
\hline & $(3.13)$ & $(2.99)$ & $(2.07)$ & $(1.61)$ \\
\hline \multirow{2}{*}{ Married } & -0.12 & -0.13 & -0.04 & -0.20 \\
\hline & $(-1.87)$ & $(-1.95)$ & $(-0.31)$ & $(-1.26)$ \\
\hline Household Income (in & $-.83 \times 10^{-2}$ & $-.86 \times 10^{-2}$ & $-.53 \times 10^{-2}$ & $-.51 \times 10^{-2}$ \\
\hline the thousand) & $(-1.43)$ & $(-1.54)$ & $(-0.54)$ & $(-0.43)$ \\
\hline Count-Emergency & -0.01 & -0.02 & -0.03 & -0.01 \\
\hline Preparations & $(-1.24)$ & $(-1.28)$ & $(-0.75)$ & $(-0.27)$ \\
\hline Metro-Fixed Effect & yes & no & yes & yes \\
\hline No of Observations & 2,383 & 2,383 & 651 & 482 \\
\hline$\chi^{2}$ & 775.44 & 758.17 & 212.85 & 153.23 \\
\hline
\end{tabular}

${ }^{\mathrm{a}}$ The numbers in parentheses below each coefficient are Z statistics for the null hypothesis of no association based on robust, asymptotic standard errors, estimated using Stata 11's probit estimation routine. 


\section{Figure 1: Information Scenarios and Question-Wording}

\section{Background}

Now we would like to ask you about a different situation. National security has always required that some information be kept secret, often for a long time. Usually the government keeps information secret because making the information public might be dangerous for the people who supplied the information to the government officials, the people involved in the activity being kept secret, or it might hurt the government's ability to protect the public from threats in the future.

At the same time, there is increasing recognition among psychologists that many people overreact to some risks. As a result some experts support changes to policies that determine what information to keep secret. Please consider each of the following situations and indicate whether you would support letting a government expert decide whether to keep the information secret in order to protect our security or our economy.

\section{Version A: Organizational Information}

Suppose Federal law enforcement has prevented a major plot to destroy airports in Los Angeles and New York. The investigators are confident all terrorists are captured.

If the Federal government announces the details of the arrests then the public would know how effective our surveillance system is and would have more confidence in the government.

However, if they announce the details of the arrests, then it might give away the techniques they used to identify the suspects and other details of the security network. This could potentially make it harder for Federal law enforcement to uncover future plots. When the suspects come to trial, the information can be protected under federal laws that limit public access to information associated with cases where there are threats to national security.

Assume that there is a 1 in $(5,10,100)$ chance that announcing details about the arrests would make it harder to uncover other plots in the future. Would you favor announcing the details of the arrests or keeping the details secret from the public?

$\square$ I would support announcing the details from the arrests

$\square$ I would not support announcing the details; I would support keeping the details secret

Version B: Target Specific Information-

Commercial Airlines

A terrorist attack on a commercial flight could lead to an irrational fear of air travel. If people are afraid to fly, this would impact the commercial airline business and potentially undermine the financial viability of major airline companies.

Some experts have recommended it would be in everyone's best interest to keep information about the cause of an airplane crash due to a terrorist attack secret from the public. This would avoid the possibility of an irrational fear of flying by the public that could have large economic effects.

The actual risk of being in a plane that was the target of a terrorist attack is extremely small. If there was a terrorist attack on a plane, the cause of the crash would be kept a secret from the public - the public would be told the crash was caused by something else. The experts believe that keeping the information about the terrorist attack secret would save the economy and the airline industry from a loss of business. Experts believe this would be in the public's best interest and it defeats the terrorist's intentions by protecting the economy.

Assume that there is a 1 in $(5,10,100)$ chance that if the government announced a terrorist attack caused a plane to crash it would cause complete disruption of the commercial airline industry that would take 5 years to recover from. Would you favor announcing that a terrorist attack caused a plane to crash or keeping the information secret from the public?

I would support announcing that a terrorist attack caused a plane crash

I would not support announcing that a terrorist attack caused a plane crash. I would support keeping the information secret from the public

Version C: Target Specific Information-

Credit System

Suppose Federal law enforcement has prevented a major terrorist plot to disrupt internet service at commercial banks that would prevent processing of credit and debit card sales for 48 hours - so no one in the U.S. would be able to use a credit or debit card for 48 hours. The investigators are confident all terrorists are captured.

If the Federal government announces the details of the arrests then the public would know how effective our surveillance system is and have more confidence in the government.

However, if they announce the details of the arrests, then it might give away the techniques they used to identify the suspects and other details of the security network. This could potentially make it harder for Federal law enforcement to uncover future plots. When the suspects come to trial, the information can be protected under federal laws that limit public access to information associated with cases where there are threats to national security.

Assume that there is a 1 in $(5,10,100)$ chance that announcing details about the arrests would make it harder to uncover other plots in the future. Would you favor announcing the details of the arrests or keeping the details secret from the public?

$\square$ I would support announcing the details from the arrests

I would not support announcing the details; I would support keeping the details secret 
